\title{
Combined detection of liver stiffness and C-reactive protein in patients with hepatitis B virus-related liver cirrhosis, with and without hepatocellular carcinoma
}

\author{
XIAO-YAN LIU ${ }^{1 *}$, LI-NA MA ${ }^{1 *}$, TING-TING YAN ${ }^{2 *}$, ZHEN-HUI LU ${ }^{3 *}$, \\ YUAN-YUAN TANG ${ }^{1 *}$, XIA LUO $^{1 *}$ and XIANG-CHUN DING ${ }^{1}$ \\ ${ }^{1}$ Department of Infectious Diseases, General Hospital of Ningxia Medical University; \\ ${ }^{2}$ Ningxia Medical University; ${ }^{3}$ Department of Hepatobiliary Surgery, General Hospital \\ of Ningxia Medical University, Yinchuan, Ningxia 750004, P.R. China
}

Received June 9, 2015; Accepted September 7, 2015

DOI: $10.3892 / \mathrm{mco} .2016 .742$

\begin{abstract}
The aim of the present study was to investigate the usefulness of combined detection of liver stiffness (LS) and serum C-reactive protein (CRP) level in patients with hepatitis B virus (HBV)-related liver cirrhosis (LC). A total of 156 cases of previously untreated patients with HBV-related LC were classified into the LC group [LC without hepatocellular carcinoma (HCC)] and the HCC group (LC with HCC). Comparative analyses of LS and serum CRP level were conducted between these two groups. LS values and serum CRP levels were found to be significantly higher in the HCC group compared with those in the LC group $(\mathrm{P}<0.01)$. The LS values and serum CRP levels were not significantly different between $\alpha$-fetoprotein (AFP)-positive and -negative patients. A high LS value was a high-risk factor for HCC in patients with chronic hepatitis B. The CRP-positive rate was significantly higher in the HCC group compared with that in LC group in a subset of patients with high LS values $(\mathrm{P}<0.01)$. In conclusion, the combined detection of LS and serum CRP may complement the measurement of AFP in the diagnosis of HBV-related HCC, improve the identification of patients with AFP-negative HCC and help distinguish HCC from LC.
\end{abstract}

Correspondence to: Dr Xiang-Chun Ding, Department of Infectious Diseases, General Hospital of Ningxia Medical University, 1160 Shengli Street, Yinchuan, Ningxia 750004, P.R. China

E-mail: 13619511768@163.com

${ }^{*}$ Contributed equally

Abbreviations: HCC, hepatocellular carcinoma; HBV, hepatitis B virus; CRP, C-reactive protein; LSM, liver stiffness measure; CHB, chronic hepatitis B

Key words: chronic hepatitis B, liver cirrhosis, hepatocellular carcinoma, FibroScan, high-sensitivity C-reactive protein

\section{Introduction}

Hepatocellular carcinoma (HCC) is the most frequent primary malignancy of the liver (1) and a prevalent malignancy with poor outcome. Approximately 600,000 new cases are diagnosed annually, among which 55\% in China (2). The majority of HCC cases $(\sim 80 \%)$ are associated with chronic hepatitis B virus $(\mathrm{HBV})$ infection-related liver cirrhosis $(\mathrm{LC})(3,4)$. The main treatment used for primary liver cancer is surgery. Asian series have reported a 5-year survival rate of $\sim 70 \%$ following resection of HCCs sized $<2 \mathrm{~cm}$, while the current 5-year survival rate of advanced liver cancer is $\sim 10 \%$, only marginally better compared with that of pancreatic cancer (5). Therefore, early diagnosis is crucial for improving the survival rate of patients with primary liver cancer. However, due to the lack of effective methods for early diagnosis, only 30-40\% of patients with primary liver cancer are timely diagnosed and treated at an early stage. The measurement of $\alpha$-fetoprotein (AFP) levels is widely used as a surveillance test for HCC (6). Several studies of AFP in HCC surveillance revealed that its sensitivity is estimated at $39-64 \%$, its specificity at $76-91 \%$, its positive predictive value at $9-32 \%$ and its negative value at $\leq 30 \%$ (6). The sensitivity, specificity and positive predictive value of ultrasound for HCC have been reported to be 71-78, 90-93 and 14-73\%, respectively. Adding ultrasound to AFP measurement in the screening of individuals at higher risk of liver cancer may significantly increase the early diagnosis rate; approximately one-third of the patients may be diagnosed and treated at an early stage. Despite the large number of studies on the immunohistochemistry of HCC, such as AFP-L3, a1,6-fucosyltransferase, glypican-3, Dickkopf-1 and heat shock protein 70 (7), absolute positive and negative markers for HCC are still lacking, and even those characterized by very high sensitivity and specificity do not exhibit universal diagnostic usefulness. Therefore, the diagnosis of HCC at an early stage remains a prerequisite for favorable prognosis.

Liver stiffness measurement (LSM) using transient elastography (TE FibroScan ${ }^{\circledR}$; Echosens, Paris, France) has been shown to be correlated with liver fibrosis in various chronic liver diseases (8-11). LSM correlates well with the stage of 
liver fibrosis and may serve as a predictor of HCC development among patients with chronic hepatitis (12-16). It remains questionable whether LSM alone may be applied as a predictive marker of primary liver cancer at the clinical setting. Therefore, it is necessary to identify markers that may be combined with liver stiffness (LS) to improve the prediction of HCC.

C-reactive protein $(\mathrm{CRP})$ is an acute-phase protein synthesized by the liver. Rapid, marked increases in CRP levels occur with inflammation, infection, trauma and tissue necrosis (17-21). Several studies have been performed on the association of CRP with the severity of inflammation in liver disease, such as fatty liver and chronic hepatitis C (22-25). A persistently elevated CRP level following initial treatment is an independent marker of a poor prognosis, and normalization of the CRP level after initial treatment is associated with improved outcome in HCC patients (26-28). As regards the ability of CRP to predict HBV-related HCC, it remains unknown. A total of $156 \mathrm{LC}$ cases with and without $\mathrm{HCC}$ were compared in terms of LS and high-sensitivity CPR (hs-CRP), to investigate the potential of combined detection of LS and serum CRP level in the diagnosis of HCC in patients with chronic hepatitis B.

\section{Patients and methods}

Patients. A total of 156 patients with HBV-related LC in our hospital were included in this study. The patients were divided into the LC group (LC without HCC) and the HCC group (LC with HCC). These cases were confirmed by clinical presentation, diagnostic ultrasound imaging and laboratory diagnosis. $\mathrm{LC}$ was diagnosed according to the guideline of prevention and treatment for chronic hepatitis B, 2010 version (29); HCC was diagnosed according to the criteria formulated by the Chinese Anti-Cancer Association. All the included patients had not been treated with any hepatoprotective, antifibrotic or antiviral drugs. In addition, 50 healthy individuals, without autoimmune or metabolic diseases, without a history of drug or alcohol abuse or other factors that may cause liver damage, and without hematological diseases, were used as the control group. Patients with conditions likely to affect the serum CRP level, such as acute infections, rheumatoid arthritis, gout, asthma, chronic lung disease, myocardial infarction and stroke, were excluded.

\section{Parameters}

$L S M$. Scanning was performed using transient elastography FibroScan ${ }^{\circledast}$ (Echosens) according to the method described in the manufacturer's instructions. The LS grading criteria were as follows: $>17.5 \mathrm{kPa}$ cirrhosis; patients were subgrouped with a 5-kPa interval into 17.5-22.5, 22.6-27.5 and $>27.6 \mathrm{kPa}$ groups.

Serum CRP levels. Measurement was performed using the latex enhanced turbidimetric method with the reagent purchased from Roche Diagnostics GmbH (Mannheim, Germany) using the Roche Modular P800 analyzer. The serum CRP normal reference range was $0-2.87 \mathrm{mg} / \mathrm{l}$, with serum hs-CRP $>2.87 \mathrm{mg} / \mathrm{l}$ considered as positive.

AFP. The plasma levels of AFP were measured using a commercial ELISA kit (Abbott Laboratories Company, Chicago, IL, USA) in accordance with the manufacturer's
Table I. LSM values and serum hs-CRP levels (mean \pm SD).

\begin{tabular}{lccc}
\hline Groups & No. & $\begin{array}{c}\text { hs-CRP } \\
(\mathrm{mg} / \mathrm{l})\end{array}$ & $\begin{array}{c}\text { LSM values } \\
(\mathrm{kPa})\end{array}$ \\
\hline Healthy & 50 & $0.78 \pm 1.07$ & $4.25 \pm 0.74$ \\
LC & 89 & $9.47 \pm 19.56$ & $27.81 \pm 18.46$ \\
HCC & 67 & $30.78 \pm 15.17$ & $39.72 \pm 29.05$ \\
t-test & & -0.964 & -1.735 \\
P-value & & 0.0337 & 0.0093 \\
\hline
\end{tabular}

LSM, liver stiffness measurement; LC, liver cirrhosis; hs-CRP, high-sensitivity $\mathrm{C}$-reactive protein; $\mathrm{HCC}$, hepatocellular carcinoma.

Table II. LSM values and serum hs-CRP levels in AFP-positive and -negative patients (mean $\pm \mathrm{SD}$ ).

\begin{tabular}{lccc}
\hline AFP status & No. & $\begin{array}{c}\text { hs-CRP } \\
(\mathrm{mg} / \mathrm{ml})\end{array}$ & $\begin{array}{c}\text { LSM values } \\
(\mathrm{kPa})\end{array}$ \\
\hline Positive & 35 & $13.58 \pm 27.16$ & $48.95 \pm 28.59$ \\
Negative & 32 & $8.66 \pm 17.72$ & $28.64 \pm 26.83$ \\
t-test & & 0.815 & 1.706 \\
P-value & & 0.419 & 1.104 \\
\hline
\end{tabular}

LSM, liver stiffness measurement; AFP, $\alpha$-fetoprotein; hs-CRP, high-sensitivity C-reactive protein.

instructions. The HCC group was divided into AFP-positive $(>20 \mathrm{ng} / \mathrm{ml})$ and -negative $(\leq 20 \mathrm{ng} / \mathrm{ml})$.

Statistical analysis. The statistical analysis was performed using the SPSS v.17.0 software package (SPSS Inc., Chicago, IL, USA). Quantitative data were analyzed using the independent-samples t-test and expressed as mean \pm standard deviation. The count data were analyzed using the $\chi^{2}$ test. $\mathrm{P}<0.05$ was considered to indicate a statistically significant difference. Correlation analyses were conducted using the Pearson's and Spearman's correlation tests.

\section{Results}

Clinical data. A total of 156 cases of previously untreated patients with LC were included, 125 of whom were men and 31 were women (mean age, $38 \pm 17.1$ years). The patients were divided into the LC group (LC without HCC, $\mathrm{n}=89$ ) and the HCC group (LC with HCC, n=67). Of the 50 healthy controls, 41 were men and 9 were women (mean age, $38 \pm 9.4$ years). The LSM values and serum CRP levels were found to be significantly higher in the HCC group compared with those in the LC group $(\mathrm{P}<0.05$ and $\mathrm{P}<0.01$, respectively; Table I).

Comparisons of LSM values and serum CRP levels in AFP-positive and-negative patients. The HCC group was subdivided into the AFP-positive (AFP $>20 \mathrm{ng} / \mathrm{ml}$ ) and AFP-negative (AFP $\leq 20 \mathrm{ng} / \mathrm{ml}$ ) groups. The LSM values and 
Table III. Proportion analysis of HCC, LSM grade and serum hs-CRP positivity rate.

\begin{tabular}{|c|c|c|c|c|c|}
\hline \multirow[b]{2}{*}{$\mathrm{LSM}$ grade $(\mathrm{kPa})$} & \multirow[b]{2}{*}{ Case (no.) } & \multicolumn{2}{|c|}{ LC group } & \multicolumn{2}{|c|}{ HCC group } \\
\hline & & $\mathrm{CRP}^{+}$, no. $(\%)$ & $\mathrm{CRP}^{-}$, no. $(\%)$ & $\mathrm{CRP}^{+}$, no. $(\%)$ & $\mathrm{CRP}^{-}$, no. $(\%)$ \\
\hline $17.5-22.5$ & 0 & $0 / 0(0.0)$ & $0 / 0(0.0)$ & $0 / 0(0.0)$ & $0 / 0(0.0)$ \\
\hline $22.6-27.5$ & 24 & $0 / 10(0.0)$ & $10 / 10(100.0)$ & 0/14 (0.0) & $14 / 14(100.0)$ \\
\hline$>27.6$ & 132 & $30 / 79(37.97)$ & $49 / 79(62.03)$ & $34 / 53(64.15)$ & $19 / 53(35.85)$ \\
\hline$\chi^{2}$ test & & \multicolumn{2}{|c|}{8.847} & \multicolumn{2}{|c|}{24.89} \\
\hline P-value & & \multicolumn{2}{|c|}{0.003} & \multicolumn{2}{|c|}{0.000} \\
\hline
\end{tabular}

LSM, liver stiffness measurement; hs-CRP, high-sensitivity C-reactive protein; HCC, hepatocellular carcinoma.

serum CRP levels were not significantly different between AFP-positive and -negative patients ( $\mathrm{P}>0.05$, Table II).

Association of LSM values and serum CRP levels with HCC. The proportional analysis of HCC and CRP positivity rate among 3 stratifications of LSM revealed that a high LSM value was a high-risk factor for HCC. In a subset of patients with LSM values $>27.6 \mathrm{kPa}$, the CRP positivity rate was significantly higher in the HCC group $(64.15 \%)$ compared with that in the LC group $(37.97 \%)(\mathrm{P}<0.01$, Table III).

\section{Discussion}

The diagnosis of HCC at an early stage is a prerequisite for improved prognosis. LSM using FibroScan transient elastography has been shown to be correlated with liver fibrosis in various chronic liver diseases. The LSM cut-off value of $17.5 \mathrm{kPa}$ is considered optimal for diagnosing LC (8-11) and the LSM value is useful in predicting HCC (12-16). Among a total of 156 patients with HBV-related cirrhosis, the LSM values were significantly higher in the HCC group $(39.72 \pm 29.05 \mathrm{kPa})$ compared with those in the LC group $(27.81 \pm 8.46 \mathrm{kPa})$ $(\mathrm{P}<0.05)$. The LSM values were not significantly different between AFP-positive and -negative patients $(\mathrm{P}>0.05)$. The cut-off value was set at $17.5 \mathrm{kPa}$, and patients were subgrouped with a 5-kPa interval into the 17.5-22.5, 22.6-27.5 and $>27.6 \mathrm{kPa}$ groups. This subgroup analysis revealed that a high LSM value ( $>27.6 \mathrm{kPa}$ ) was a high-risk factor for $\mathrm{HCC}$, which was consistent with earlier findings, indicating the usefulness of LSM in predicting HCC. Furthermore, it was observed that $59.85 \%$ of patients with LSM values of $>27.6 \mathrm{kPa}$ did not have HCC. This positive predictive value was significantly lower compared with that of ultrasound combined with AFP. Therefore, it is necessary to identify markers to combine with LS in order to improve the prediction of HCC.

The majority of the cases of HCC are associated with cirrhosis related to chronic hepatitis $(1,3,9)$. CRP is an acute-phase protein synthesized by the liver. Several studies have been performed to determine the association of CRP with the severity of inflammation in liver diseases, such as fatty liver and chronic hepatitis C. A persistently elevated CRP level following initial treatment is an independent marker of a poor prognosis, and normalization of the CRP level after initial treatment is associated with an improved outcome in HCC patients (17-29). We observed that serum CRP levels were significantly higher in the HCC group $(30.78 \pm 15.17 \mathrm{mg} / \mathrm{l})$ compared with those in the LC group $(9.47 \pm 19.56 \mathrm{mg} / \mathrm{l})(\mathrm{P}<0.01)$, whereas they were not significantly different between AFP-positive and -negative patients $(\mathrm{P}>0.05)$. These results may be explained by the fact that AFP-positive HCC patients may have larger tumors and exhibit more severe inflammation due to the invasion of the portal system. The cut-off value for LSM was set at $17.5 \mathrm{kPa}$, and patients were subgrouped with a 5-kPa interval into 17.5-22.5, 22.6-27.5 and $>27.6 \mathrm{kPa}$ groups. Patients with serum CRP levels $>2.87 \mathrm{mg} / \mathrm{l}$ were defined as positive, whereas those with serum CRP levels $<2.87 \mathrm{mg} / \mathrm{l}$ were defined as negative. A proportion analysis was performed of HCC and serum CRP positivity rate among the 3 LSM grades. It was demonstrated that a high LSM value was a high-risk factor for HCC. In a subset of patients with LSM values $>27.6 \mathrm{kPa}$, the CRP positivity rate was significantly higher in the HCC group (64.15\%) compared with that in the LC group $(37.97 \%)(\mathrm{P}<0.01)$. These results demonstrate the association of HCC with combined detection of LS and serum CRP.

In conclusion, the combined detection of LS and serum CRP may complement the measurement of AFP level in the diagnosis of HBV-related HCC, facilitate the identification of patients with AFP-negative HCC, and help distinguish HCC from LC.

\section{Acknowledgements}

This study was supported by grants from the National Natural Science Foundation of China (grant no. 81460301), the Natural Science Foundation of Ningxia (grant nos. NZ09115 and NZ11199), and the Scientific and Technological Foundation of Ningxia and Chinese Foundation for Hepatitis Wang Bao-En Liver Fibrosis Fund (grant no. xjs).

\section{References}

1. El-Serag HB: Epidemiology of viral hepatitis and hepatocellular carcinoma. Gastroenterology 142: 1264-1273, 2012.

2. Luk JM and Liu AM: Proteomics of hepatocellular carcinoma in Chinese patients. OMICS 15: 261-266, 2011.

3. Lin CL and Kao JH: Risk Stratification for hepatitis B virus related hepatocellular carcinoma. J Gastroenterol Hepatol 28: $10-17,2013$

4. Gao Y, Jiang Q, Zhou X, Ding B, Wang R, Zhao G and Chen Y: HBV infection and familial aggregation of liver cancer: An analysis of case-control family study. Cancer Causes Control 15: 845-850, 2004 
5. Siegel R, Naishadham D and Jemal A: Cancer statistics, 2013. CA Cancer J Clin. 63: 11-30, 2013.

6. Cabrera R, Fitian AI, Ararat M, Xu Y, Brusko T, Wasserfall C, Atkinson MA, Liu C and Nelson DR: Serum levels of soluble CD25 as a marker for hepatocellular carcinoma. Oncol Lett 4: 840-846, 2012.

7. Masuzaki R, Karp SJ and Omata M: New serum markers of hepatocellular carcinoma. Semin Oncol 39: 434-439, 2012.

8. Marcellin P, Ziol M, Bedossa P, Douvin C, Poupon R, de Lédinghen $\mathrm{V}$ and Beaugrand $\mathrm{M}$ : Non-invasive assessment of liver fibrosis by stiffness measurement in patients with chronic hepatitis B. Liver Int 29: 242-247, 2009.

9. Kim do Y, Kim SU, Ahn SH, Park JY, Lee JM, Park YN, Yoon KT, Paik YH, Lee KS, Chon CY, et al: Usefulness of FibroScan for detection of early compensated liver cirrhosisin chronic hepatitis B. Dig Dis Sci 54: 1758-1763, 2009.

10. Chan HL, Wong GL, Choi PC, Chan AW, Chim AM, Yiu KK, Chan FK, Sung JJ and Wong VW: Alanine aminotransferase-based algorithms of liver stiffness measurement by transient elastography (Fibroscan) for liver fibrosis in chronic hepatitis B. J Viral Hepat 16: 36-44, 2009.

11. Vizzutti F1, Arena U, Romanelli RG, Rega L, Foschi M, Colagrande S,Petrarca A, Moscarella S,BelliG,Zignego AL et al: Liver stiffness measurement predicts severe portal hypertension in patients with HCV-related cirrhosis. Hepatolog 45: 1290-1297, 2007.

12. Cescon M, Colecchia A, Cucchetti A, Peri E, Montrone L, Ercolani G, Festi D and Pinna AD: Value of transient elastography measured with FibroScan in predicting the outcome of hepatic resection for hepatocellular carcinoma. Ann Surg 256: 706-712; discussion 712-713, 2012

13. Masuzaki R, Tateishi R, Yoshida H, Goto E, Sato T, Ohki T, Imamura J, Goto T, Kanai F, Kato N, et al: Prospective risk assessment for hepatocellular carcinoma development in patients with chronic hepatitis $\mathrm{C}$ by transient elastography. Hepatology 49 : 1954-1961, 2009

14. Jung KS, Kim SU, Ahn SH, Park YN, Kim do Y, Park JY, Chon CY, Choi EH and Han KH: Risk assessment of hepatitis B virus-related hepatocellular carcinoma development using liver stiffness measurement (FibroScan). Hepatology 53: 885-894, 2011.

15. Fung J, Lai CL, Seto WK, Wong DK and Yuen MF: Prognostic significance of liver stiffness for hepatocellular carcinoma and mortality in HBeAg-negative chronic hepatitis B. J Viral Hepat 18: 738-744, 2011.

16. Chon YE, Jung ES, Park JY, Kim do Y, Ahn SH, Han KH, Chon CY, Jung KS and Kim SU: The accuracy of noninvasive methods in predicting the development of hepatocellular carcinoma and hepatic decompensation in patients with chronic hepatitis B. J Clin Gastroenterol. 46: 518-525, 2012.

17. Shameem M, Bhargava R, Ahmad Z, Saad T, Fatima N and Malik A: Association between serum C-reactive protein levels and other important predictive markers of outcome in COPD. Acta Med Iran 49: 18-20, 2011

18. Tasxi C, BalkanA, Karadurmus N, Inal S, Kilic S, Ozkan M, Bilgic $\mathrm{H}$ and Ekiz K: The importance of serum procalcitonin levels in patients with chronic obstructive pulmonary disease exacerbations. Turk J Med Sci 38: 139-144, 2008.

19. Garcia-Rio F, Miravitlles M, Soriano JB, Muñoz L, Duran-Tauleria E, Sánchez G, Sobradillo V and Ancochea J EPI-SCAN Steering Committee: Systemic inflammation in chronic obstructive pulmonary disease: A population-based study. Respir Res 11: 63, 2008.
20. Peisajovich A, Marnell L, Mold C and Du Clos TW: C-reactive protein at the interface between innate immunity and inflammation. Expert Rev Clin Immunol 4: 379-390, 2008.

21. Dinarello CA: The acute phase response. In: Cecil Textbook of Medicine, 20th edition, Bennett JC and Plum F (eds). WB Saunders Co., pp1535-1537, 1996.

22. Andreozzi P, Viscogliosi G, Colella F, Subic M, Cipriani E, Marigliano B, Verrusio W, Servello A,Ettorre E and Marigliano V: Predictors of liver fibrosis in patients with non-alcoholic fatty liver disease. The role of metabolic syndrome, insulin-resistance and inflammation. Recenti Prog Med 103: 570-574, 2012.

23. Ma LN, Liu XY, Luo X, Hu YC, Liu SW, Tang YY, Pan JL and Ding XC. Serum high-sensitivity C-reactive protein are associated with HBV replication, liver damage and fibrosis in patients with chronic hepatitis B. Hepatogastroenterology 62: 368-372, 2015.

24. Atta M, Cabral M, Santos G, Paraná R and Atta A: Inflammation biomarkers in chronic hepatitis $\mathrm{C}$ : Association with liver histopathology, HCV genotype and cryoglobulinemia. Inflamm Res 61: 1101-1106, 2012.

25. Sjöwall C1, Cardell K, Boström EA, Bokarewa MI, Enocsson H, Ekstedt M, Lindvall L, Frydén A and Almer S: High prevalence of autoantibodies to $\mathrm{C}$-reactive protein in patients with chronic hepatitis $\mathrm{C}$ infection: association with liver fibrosis and portal inflammation. Hum Immunol 73: 382-388, 2012.

26. Nishikawa H, Arimoto A, Wakasa T, Kita R, Kimura T and Osaki Y: Pre-treatment C-reactive protein as a prognostic factor for recurrence after surgical resection of hepatocellular carcinoma. Anticancer research 33: 1181-1188, 2013.

27. Chen W, Wang JB, Abnet CC, Dawsey SM, Fan JH, Yin LY, Y in J, Taylor PR, Qiao YL and Freedman ND: Association between C-reactive protein, incident liver cancer, and chronic liver disease mortality in the Linxian Nutrition Intervention Trials: A nested case-control study. Cancer Epidemiol Biomarkers Prev 24: 386-392, 2015.

28. Zhao X, Luo J, Li B, Liu S and Li D: The association between preoperative serum C-reactive protein and hepatocellular carcinoma recurrence in patients with chronic hepatitis $\mathrm{B}$ virus (HBV) infection-a retrospective study. PLoS One 10: e0116909, 2015.

29. Chinese Society of Hepatology and Chinese Society of Infectious Diseases, Chinese Medical Association: The guideline of prevention and treatment for chronic hepatitis B (2010 version). Chin J Hepatol 19: 13-24, 2011 (In Chinese). 